\title{
Performance Improvement of a Centrifugal Compressor by Passive Means
}

\author{
N. Sitaram ${ }^{1}$ and S. M. Swamy ${ }^{1,2}$ \\ ${ }^{1}$ Thermal Turbomachines Laboratory, Department of Mechanical Engineering, Indian Institute of Technology Madras, \\ Chennai 600 036, India \\ ${ }^{2}$ Department of Mechanical Engineering, GNITS, Shaikpet, hyderabad 500 008, India \\ Correspondence should be addressed to N. Sitaram, nsitaram@iitm.ac.in
}

Received 14 January 2012; Revised 15 April 2012; Accepted 15 April 2012

Academic Editor: Ashwani K. Gupta

Copyright (๑) 2012 N. Sitaram and S. M. Swamy. This is an open access article distributed under the Creative Commons Attribution License, which permits unrestricted use, distribution, and reproduction in any medium, provided the original work is properly cited.

The present experimental investigation deals with performance improvement of a low-speed centrifugal compressor by inexpensive passive means such as turbulence generator placed at different positions and partial shroud near the rotor blade tip. The experiments are carried out at three values of tip clearance, namely $2.2 \%, 5.1 \%$, and $7.9 \%$ of rotor blade height at the exit. Performance tests are carried out for a total of 13 configurations. From these measurements, partial shroud is found to give the best performance. The improvement in the compressor performance may be due to the reduction of tip leakage flows by the small extension of partial shroud ( $2 \mathrm{~mm}$ on the pressure surface side). Although there is nominal change in performance due to turbulence generator (TG), TG has beneficial effect of increased operating range.

\section{Introduction}

The centrifugal compressors have a wide range of applications especially for power plants for small aircraft and helicopters, in process industries, compression of gases and vapours, and refrigeration, because they can provide highpressure ratios and large operating ranges with relatively high efficiencies. Centrifugal compressors are used primarily for their suitability for handling small volume flows, but other advantages include a shorter length than an equivalent axial flow compressor, less susceptibility to loss of performance by buildup of deposits on the blade surfaces, and their suitability to operate over a wide range of mass flow. The efficiency of a centrifugal compressor is lower than that of an axial flow compressor. Efficiency is probably the most important performance parameter for turbomachines. The conditions of flow in the tip region of rotor blades are very complex due to strong interaction of the leakage flow with the boundary layers and secondary flows. The tip leakage flow thus would have dominant effect on the performance of a compressor. A comprehensive review of tip clearance effects in centrifugal compressors is given by Pampreen [1]. Senoo and Ishida [2] gave analytical expression to quantify the tip clearance effects in centrifugal blowers. Senoo [3] gave a comprehensive review of mechanics of tip leakage flows in axial and centrifugal compressors. Ishida et al. [4] had tested centrifugal blowers with different shapes (square, round, and E-type, i.e., with an extension on the pressure surface side) and found that E-type tip provided improved performance. The concept of partial shrouded rotor in a small high-speed high-pressure ratio centrifugal compressor was computationally investigated by Tang et al. [5]. They found that the leakage flow was reduced in the partially shrouded rotor. Recently, Akturk and Camci [6] measured three-dimensional mean flow near the tip of a ducted axial fan rotor using a stereoscopic particle image velocimeter. A number of novel tip treatments based on custom-designed pressure side extensions were tested to mitigate tip leakage flow. The chordwise location and the width of the extension in the circumferential direction are systematically varied. Tip platform extensions near the rotor blade trailing edge were found to show the best tip treatment performance. They $[7,8]$ further carried out computational and experimental investigations on additional tip treatments. Kameier and 
TABLE 1: Design details of the rotor.

\begin{tabular}{lc}
\hline Total pressure rise, $\Delta p$ & $300 \mathrm{~mm} \mathrm{WG}$ \\
Volume flow rate, $V$ & $1.12 \mathrm{~m}^{3} / \mathrm{s}$ \\
Speed of rotation, $N$ & $2000 \mathrm{rpm}$ \\
Shape number, $N_{\mathrm{sh}}$ & 0.092 \\
No. of rotor blades, $Z$ & 16 \\
Inducer hub diameter, $d_{1 \mathrm{~h}}$ & $160 \mathrm{~mm}$ \\
Inducer tip diameter, $d_{1 \mathrm{t}}$ & $300 \mathrm{~mm}$ \\
Rotor tip diameter, $d_{2}$ & $500 \mathrm{~mm}$ \\
Blade height at the exit, $h_{2}$ & $32.5 \mathrm{~mm}$ \\
Blade thickness & $3 \mathrm{~mm}$ \\
Blade angle at inducer tip, $\beta_{1 \mathrm{t}}$ & $35^{\circ}$ \\
Blade angle at inducer hub, $\beta_{1 \mathrm{~h}}$ & $53^{\circ}$ \\
\hline
\end{tabular}

Blade angle at exit, $\beta_{2}$

(a) At hub: $75^{\circ}$

(b) At mean section: $90^{\circ}$

(c) At tip: $105^{\circ}$

All the angles are measured w. r. t. tangential direction

Neise [9] had used Velcro tape in the radial clearance of an axial compressor to improve its aerodynamic and acoustic performance. Sitaram and Thakar [10] had applied this technique in a low aspect ratio axial fan and found that its performance was improved, even though the Velcro tape was placed upstream of the rotor. Any simple passive means to improve the efficiency and operating range of centrifugal compressors is very useful. The present investigation is undertaken with the objective of testing the efficacy of inexpensive passive means, such as turbulence generator (TG) and partial shrouds (PSs) to achieve increased operating range and efficiency of a centrifugal compressor. These passive devices are tested individually and in combination to arrive at the best combination.

\section{Experimental Facility, Passive Means, and Instrumentation}

2.1. Experimental Facility. The present experimental investigations are carried out on a low-speed centrifugal compressor setup available in Thermal Turbomachines Laboratory, Department of Mechanical Engineering, Indian Institute of Technology Madras. A schematic layout of the experimental setup is shown in Figure 1. The experimental set up consists of essentially a centrifugal rotor driven by a $5 \mathrm{~kW}$ D.C. motor with a rated speed of $2000 \mathrm{rpm}$. The D.C. motor is directly coupled to the shaft carrying the rotor.

The main components of the compressor are suction duct, rotor, vaneless diffuser formed by the front and rear walls of the casing and volute casing of circular cross-section, and a delivery duct with a throttle at its outlet and nozzle at the inlet. The major design details of the compressor are given in Table 1.

2.2. Passive Means. Two inexpensive passive means, namely, turbulence generator and partial shrouds, are used in the
TABle 2: Configurations tested.

\begin{tabular}{lccc}
\hline$\tau(\%)$ & $2.2 \%$ & $5.1 \%$ & $7.9 \%$ \\
$\begin{array}{l}\text { Basic configuration } \\
\text { (without passive device) }\end{array}$ & Config. 1 & Config. 9 & Config. 12 \\
With TG only & Config. 3 & Config. 10 & Config. 11 \\
With PS only & Config. 6 & Config. 7 & Config. 14 \\
With TG + PS & Config. 5 & Config. 8 & Config. 15 \\
With TG* only & Config. 2 & - & - \\
With TG** + TG & Config. 4 & - & - \\
With TG*** only & - & - & Config. 13
\end{tabular}

TG: turbulence generator on the casing at $15 \mathrm{~mm}$ upstream of inducer tip leading edge.

$\mathrm{TG}^{*}$ : turbulence generator on the casing at $30 \mathrm{~mm}$ upstream of inducer tip leading edge.

$\mathrm{TG}^{* *}$ : turbulence generator on the hub at $30 \mathrm{~mm}$ upstream of inducer hub leading edge.

$\mathrm{TG}^{* * *}$ : turbulence generator on the casing at $400 \mathrm{~mm}$ dia.

PS: partial shrouds on the tip of the blade.

present investigation. The details of the passive means are given below.

Turbulence Generator. Turbulence generator is used in the experiment as a tripping device for the generation of turbulent boundary layers. A turbulence generator (TG) is attached to the inside of the suction duct upstream of the rotor. The turbulence generator (TG) is made of Velcro tape. The Velcro tape is attached to the inside of the suction duct. The axial width of Vecro tape is $10 \mathrm{~mm}$, the length is $942.5 \mathrm{~mm}$, and the thickness is $2 \mathrm{~mm}$. A mild steel ring of $16 \mathrm{~mm}$ axial width, $3 \mathrm{~mm}$ thickness, and $930 \mathrm{~mm}$ length was used to fix the Velcro tape to the suction duct. A layer of Araldite of very small thickness was used between the tape and the casing wall to attach the tape. The ring exerted uniform circumferential pressure all around the tape. The extra Araldite came out of the gap between the suction duct wall and the Velcro tape and removed. It was observed that the time taken for the Araldite to harden was minimized and the thickness of hardened Araldite was more or less uniform. Also, there was no sag of Velcro tape, and there was no gap between Velcro tape and suction duct.

Partial Shrouds. The partial shrouds were made of stainless steel shims of $0.1 \mathrm{~mm}$ thickness. The stainless steel shim was cut to the shape of rectangle pieces of $50 \mathrm{~mm} \times 5 \mathrm{~mm}$ size. These rectangle pieces were pasted on the tip of the blades using an extremely thin layer of Araldite.

Various configurations were obtained by combining TG and PS. Performance of the configurations with these configurations was measured and compared at three values of tip clearance, namely, $2.2 \%, 5.1 \%$, and $7.9 \%$ of rotor blade height at the exit. The details of the configurations tested are given in Table 2 and shown in Figure 2. The blade-to-blade view showing the partial shroud on the rotor blade tip is also shown in Figure 2. 


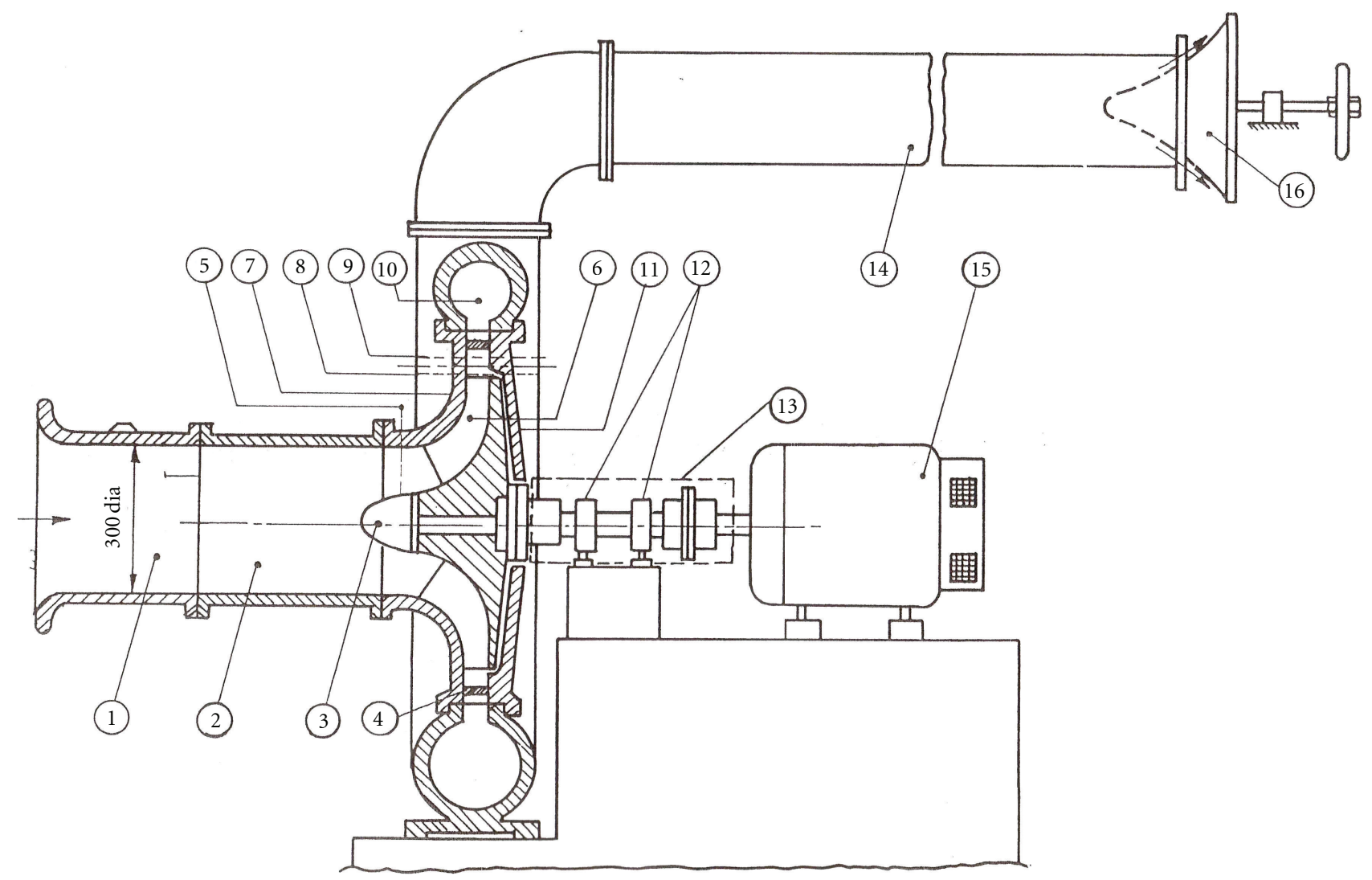
(1) Inlet nozzle
(9) Position of probe at exit 2
(2) Suction duct
(10) Volute casing
(3) Bullet nose
(11) Diffuser hub
(4) Spacers
(12) Bearing housings
(5) Position of inlet probe
(13) Bearing housing cover
(6) Rotor
(14) Delivery duct
(7) Diffuser shroud
(15) D. C. motor
(8) Position of probe at exit 1
(16) Throttle

FIgURE 1: Schematic diagram of centrifugal compressor setup.

2.3. Instrumentation. The performance of the compressor was determined by the change in the static pressure across the compressor. The static pressures on the suction duct and delivery duct were measured using a scanning box (Model FC091-3) and micromanometer (Model FCO12) manufactured by M/s Furness Control Ltd., Bexhill, UK The scanning box contained 20 valves, which are numbered sequentially. The pressures to be measured were connected to the numbered inputs. Pressure inputs were read in sequence by using the micromanometer. The micromanometer is a sensitive differential pressure measuring unit, capable of reading air pressures from $0.01 \mathrm{~mm}$ to $2000 \mathrm{~mm}$ WG. It would respond to pressure inputs up to $50 \mathrm{~Hz}$. But the time constant potentiometer can be used to average the pressure fluctuations.

The speed of the centrifugal compressor was measured using a noncontact type digital tachometer. Four interconnected static pressure tappings on the inlet bell mouth casing wall at the throat section were used to determine the inlet velocity. Knowing the bellmouth area, the volume flow was calculated using a suitable value of coefficient of discharge for the bellmouth. A D.C. motor with a separate exciter is used to drive the rotor of the centrifugal compressor. The input power was measured by means of voltmeters 


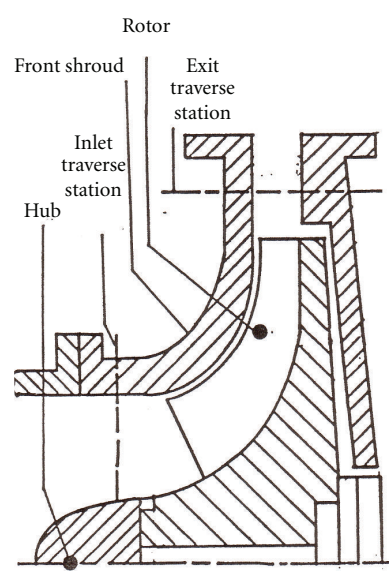

Basic configuration

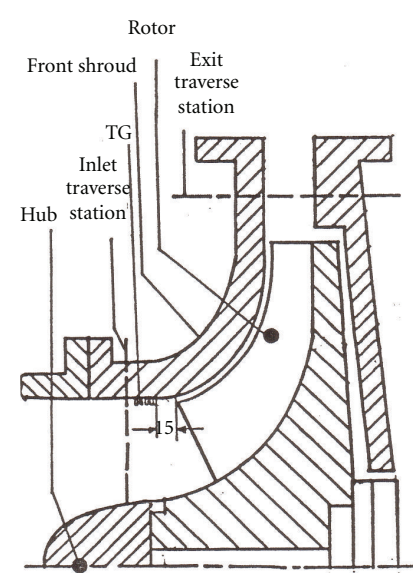

Configuration with TG only
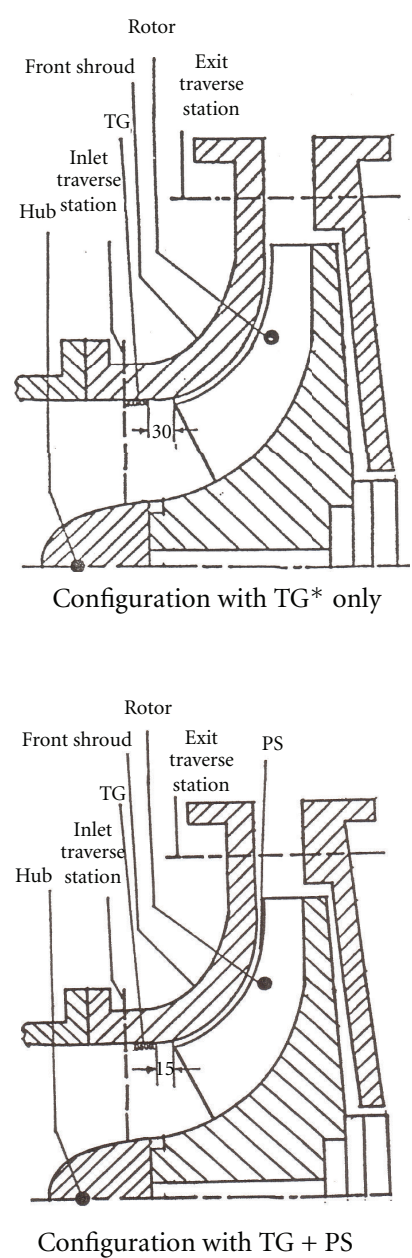
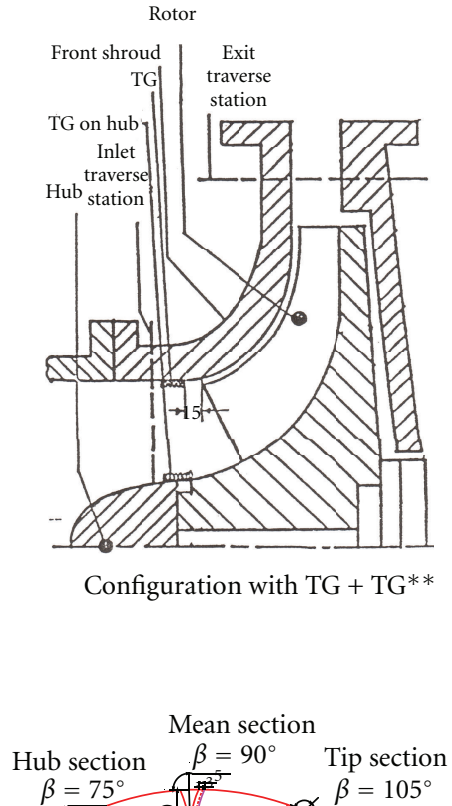
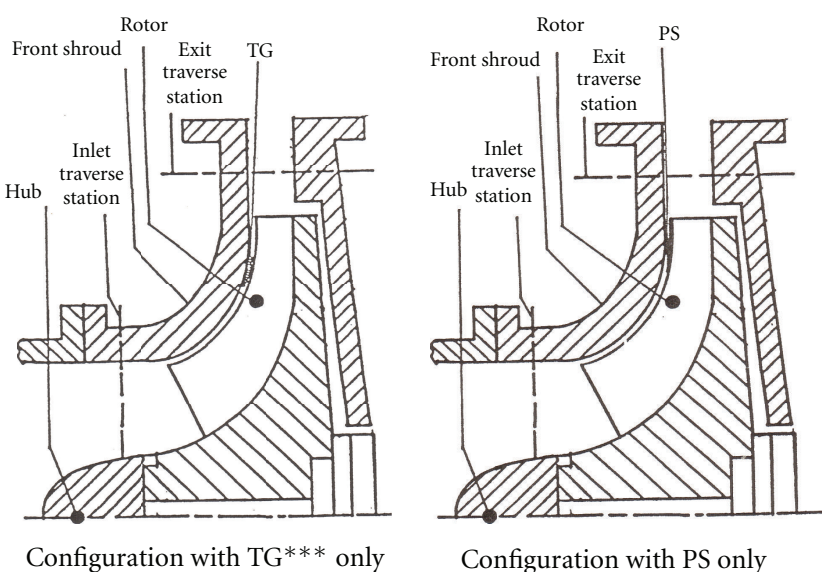

Figure 2: Details of configurations tested.

and ammeters connected separately for field and armature supplies. A suitable value of motor efficiency was used to get the rotor input power.

\section{Results and Discussion}

The results of the present investigation are presented and discussed in this section. The performance of the compressor in terms of $\psi$ versus $\phi$ and $\eta$ versus $\phi$ is presented. The nondimensional parameters are defined as follows.

Flow coefficient:

$$
\phi=\frac{V}{\pi d_{2} b_{2} U_{2}}=\frac{c_{2 r}}{U_{2}},
$$

where $V$ is the volume flow $\left(\mathrm{m}^{3} / \mathrm{s}\right)=\pi d_{2} b_{2} c_{2 r}, d_{2}$ the rotor tip diameter $(\mathrm{m}), b_{2}$ the rotor blade width at exit $(\mathrm{m}), c_{2 r}$ the radial velocity at rotor exit $(\mathrm{m} / \mathrm{s})$, and $U_{2}$ the rotor tip speed $(\mathrm{m} / \mathrm{s})$.

Energy coefficient:

$$
\psi=\frac{2 W}{U_{2}^{2}},
$$

where $W$ is the specific work $\left(\mathrm{m}^{2} / \mathrm{s}^{2}\right)=\left(p_{d}-p_{s}\right) / \rho+\left(c_{d}^{2}-\right.$ $\left.c_{s}^{2}\right) / 2+g \Delta z$.
Power coefficient:

$$
\gamma=\frac{2 N_{c}}{\rho A U_{2}^{3}}=\frac{2 \eta_{m} E I}{\rho A U_{2}^{3}},
$$

where $N_{c}$ is the coupling power (Watts) $=\eta_{m} E I, E$ the motor voltage (Volts), $I$ the motor current (Amps), $\eta_{m}$ the motor efficiency, and $A$ the suction duct area $\left(\mathrm{m}^{2}\right)$.

Compressor efficiency,

$$
\eta=\frac{\rho V W}{N_{c}} .
$$

3.1. Effect of Configuration. Figure 3 shows the performance characteristic in terms of energy coefficient, $\psi$, versus flow coefficient, $\phi$, for the three values of tip clearance. For $\tau=$ $2.2 \%$, although the effect of TG and TG* is to reduce $\psi$, stable operating range is slightly increased. The flow coefficient where maximum energy coefficient, $\psi_{\max }$, occurs is reduced. When $\mathrm{TG}^{* *}$ is placed on the rotating hub, along with TG on the stationary casing, the energy coefficient is reduced substantially.

The effect of TG on the performance curves is nominal at lower values of clearance. However, at the higher value 


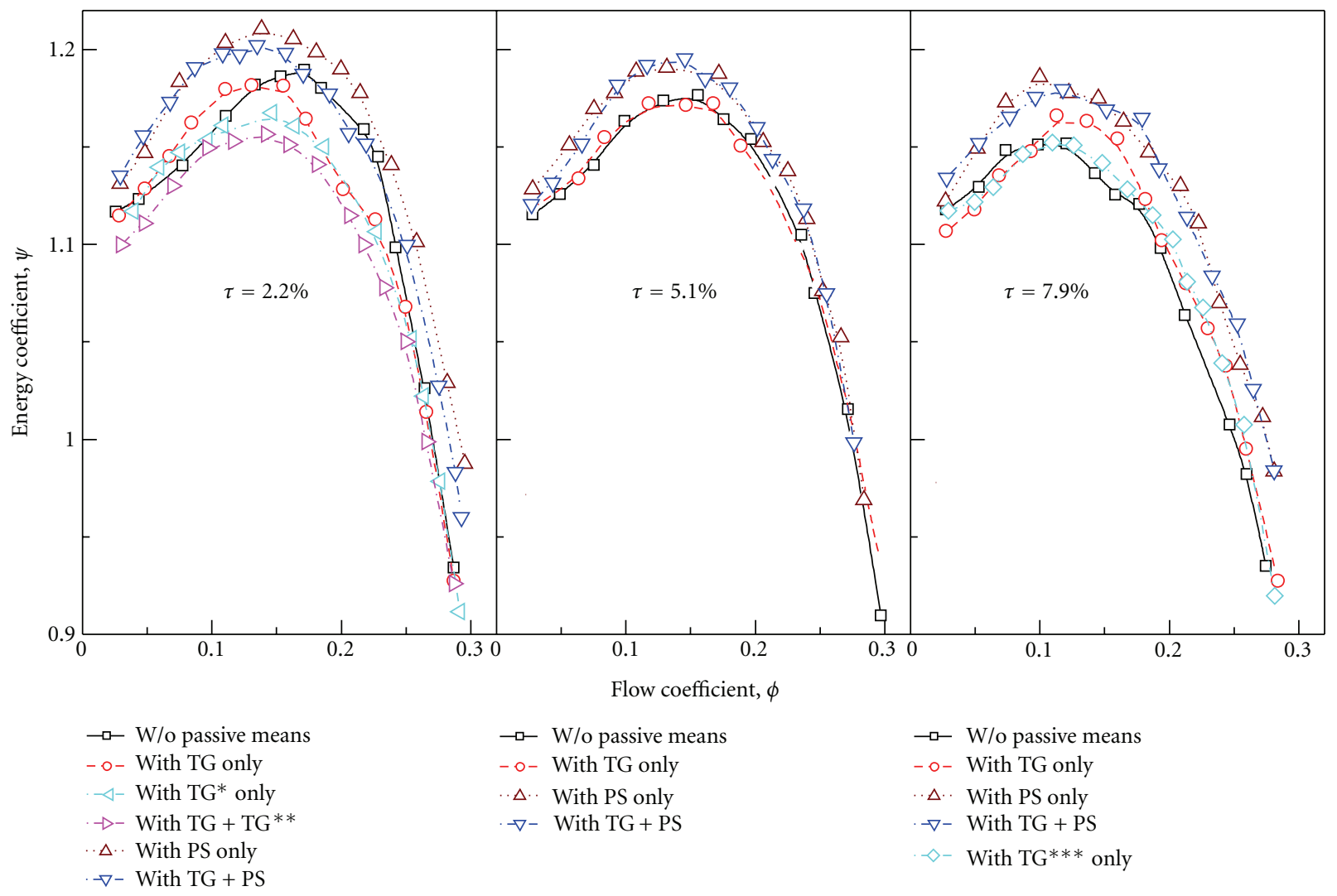

FIgURE 3: Performance characteristics of the centrifugal compressor ( $\psi$ versus $\phi)$ : effect of configuration.

of clearance of $7.9 \%$, appreciable increase in $\psi$ is achieved, with a small increase in stable operating range. The effect of $\mathrm{TG}^{* * *}$ placed in the clearance at a diameter of $400 \mathrm{~mm}$ is negligible. TG had shown beneficial effects on the performance of axial rotors $[9,10]$. The low momentum fluid in the casing wall boundary layer is energized by the TG. In centrifugal rotors, although the low momentum fluid is energized by TG, the boundary layer travels through a highly curved channel. So TG may not have substantial impact on the performance. However, at the higher value of tip clearance, some beneficial effects are observed.

The effect of the partial shroud is to improve the compressor performance, in terms of increased $\psi$ and $\eta$, at the three values of tip clearance tested. The value of $\phi$ where $\psi_{\max }$ occurs is reduced, thereby increasing stable operating range. Although performance is measured up to the maximum volume flow, for the sake of clarity of presentation, performance curves for all $\psi$ versus $\phi$ curves are limited to $\phi=0.30$. However, for $\eta$ versus $\phi$ curves (Figure 4 ), complete range of performance is presented, that is, up to the maximum value of $\phi$ of 0.40 . The values of $\psi_{\max }$ and $\phi$ where $\psi_{\max }$ occurs for all configurations are given in Table 3 . The trends of performance curves $\eta$ versus $\phi$ are similar to those of $\psi$ versus $\phi$ curves. Configurations with PS clearly show higher efficiencies as much as $5 \%$. Because of the extension of the partial shroud, the tip leakage flow has to travel a longer distance before interacting with the main flow. The contraction coefficient across the tip clearance reduces, reducing the tip leakage flow and losses. Hence, both performance and efficiency of the rotor with partial shroud are improved compared to those for the rotor without partial shroud. The tip leakage flow is stronger near the exit of the rotor, due to higher loading. Hence, partial shroud on the rotor in this region has substantial effects. The present experiments are carried out with one configuration of partial shroud. There is further scope to experiment with length and width of the partial shroud to arrive at the best partial shroud.

The most important performance parameters showing the effect of configuration are presented in Table 3. It can be concluded that partial shroud has beneficial effects on the performance of the compressor, whereas the effect of TG is nominal, except at higher value of tip clearance. In the present experiments, partial shroud with a very small extension of $2 \mathrm{~mm}$ on the pressure surface side of the rotor blade is provided. The possible reason for the improvement in the compressor performance due to this small extension may be the reduction of tip leakage flows, due to reduction of contraction coefficient.

It must be emphasized here that the performance presented above includes not only losses in the rotor but also losses in the diffuser, volute, and downstream duct with $90^{\circ}$ bends. 


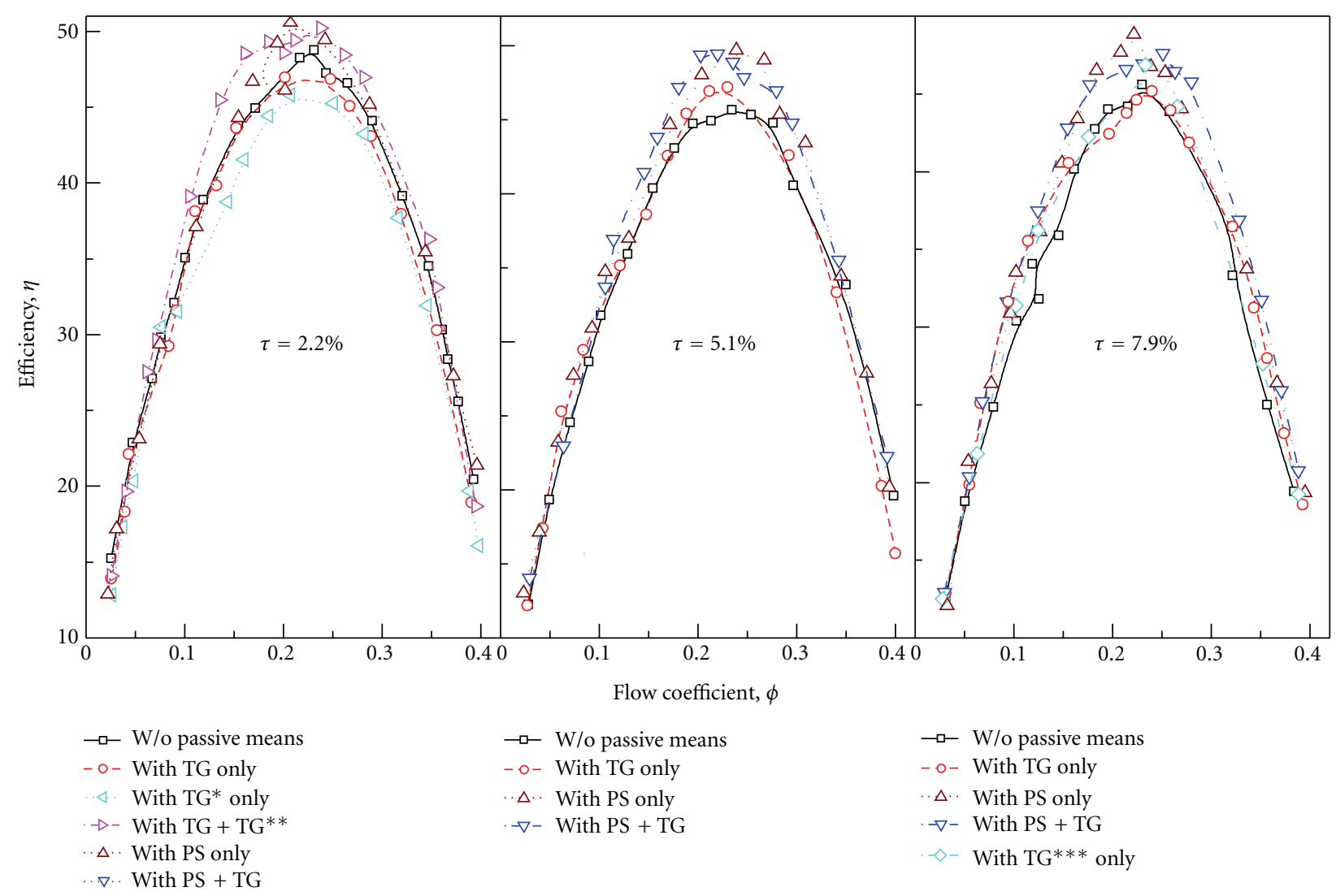

FIgURE 4: Performance characteristics of the centrifugal compressor ( $\eta$ versus $\phi)$ : effect of configuration.

TABLE 3: Effect of configuration on performance.

\begin{tabular}{|c|c|c|c|c|c|c|}
\hline$\tau(\%)$ & Details of configuration & $\psi_{\max }$ & $\phi$ at $\psi_{\max }$ & $\eta$ at $\psi_{\max }$ & $\eta_{\max }$ & $\phi$ at $\eta_{\max }$ \\
\hline 2.2 & Without passive means & 1.188 & 0.169 & 44.5 & 47.1 & 0.217 \\
\hline 2.2 & $\mathrm{TG}^{*}$ only & 1.173 & 0.124 & 39.0 & 48.2 & 0.262 \\
\hline 2.2 & TG only & 1.191 & 0.132 & 38.8 & 47.6 & 0.250 \\
\hline 2.2 & $\mathrm{TG}+\mathrm{TG}^{* *}$ & 1.156 & 0.143 & 37.8 & 45.7 & 0.217 \\
\hline 2.2 & $\mathrm{TG}+\mathrm{PS}$ & 1.205 & 0.135 & 40.0 & 50.0 & 0.207 \\
\hline 2.2 & PS only & 1.204 & 0.139 & 44.8 & 49.7 & 0.237 \\
\hline 5.1 & Without passive means & 1.173 & 0.156 & 39.9 & 45.4 & 0.237 \\
\hline 5.1 & TG only & 1.172 & 0.121 & 34.7 & 48.0 & 0.250 \\
\hline 5.1 & PS only & 1.186 & 0.109 & 34.6 & 49.4 & 0.241 \\
\hline 5.1 & TG + PS & 1.192 & 0.146 & 40.9 & 49.3 & 0.237 \\
\hline 7.9 & Without passive means & 1.153 & 0.121 & 31.9 & 45.5 & 0.230 \\
\hline 7.9 & TG only & 1.167 & 0.113 & 35.2 & 44.9 & 0.241 \\
\hline 7.9 & PS only & 1.185 & 0.101 & 33.5 & 48.6 & 0.222 \\
\hline 7.9 & $\mathrm{TG}+\mathrm{PS}$ & 1.170 & 0.128 & 33.9 & 46.8 & 0.248 \\
\hline 7.9 & $\mathrm{TG}^{* * *}$ & 1.157 & 0.124 & 38.5 & 45.2 & 0.225 \\
\hline
\end{tabular}

3.2. Effect of Tip Clearance. In order to determine the effect of tip clearance on the performance of the compressor with and without passive means, the performance curves in terms of $\psi$ versus $\phi$ and $\eta$ versus $\phi$ are replotted for the four configurations, namely, without passive means, with TG only, with PS only, and with TG + PS for the three values of tip clearances tested, that is, $\tau=2.2 \%, 5.1 \%$, and $7.9 \%$.
The $\psi$ versus $\phi$ curve (Figure 5) shows that the operating range of the compressor is increased, for the basic configuration, as the tip clearance is increased. Similar results are observed in a low-speed radial tipped centrifugal compressor [11] and a high-speed centrifugal compressor [12]. The effect of passive means (i.e., TG, PS, and TG + PS) is to reduce this trend. For both configurations, TG and TG + PS, $\psi_{\max }$ occurs 


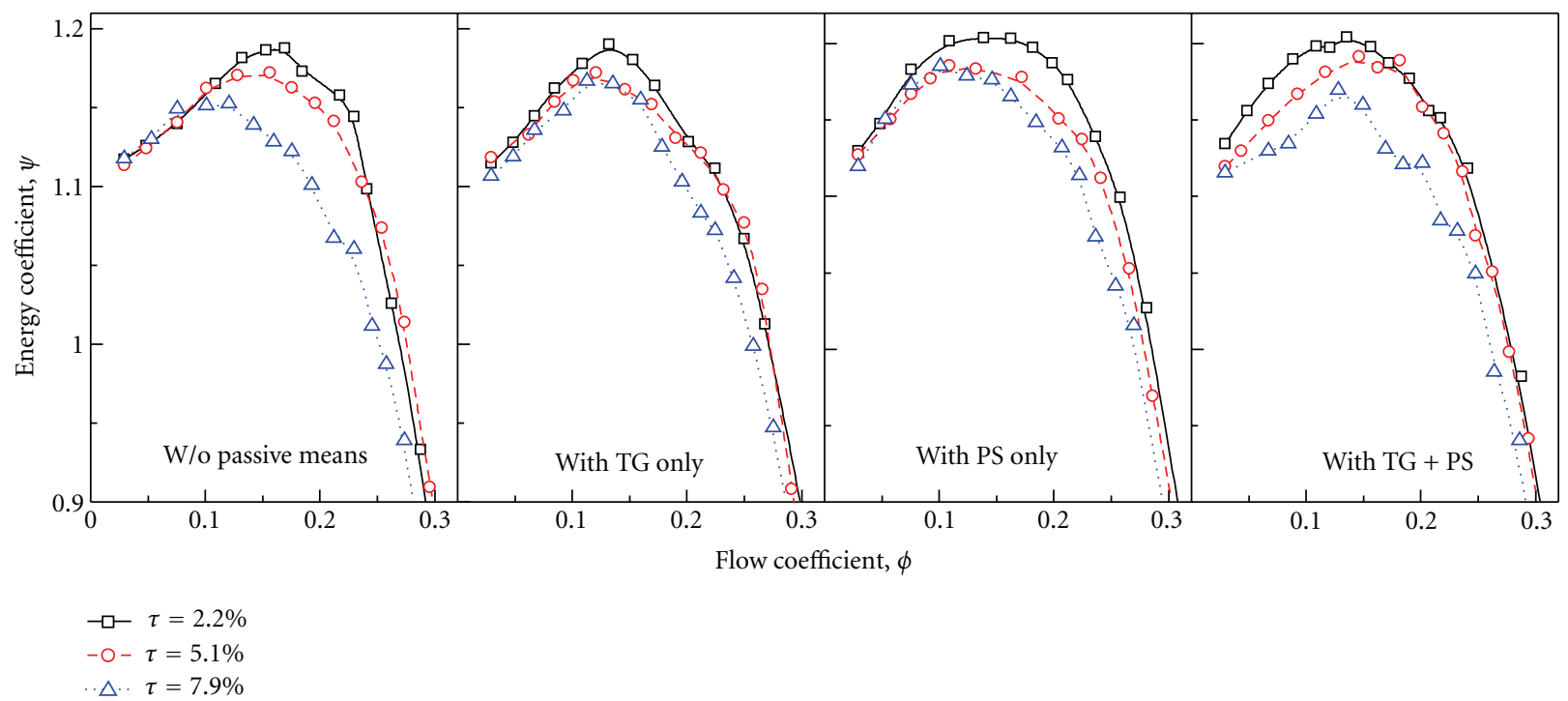

Figure 5: Performance characteristics of the centrifugal compressor ( $\psi$ versus $\phi)$ : effect of tip clearance.

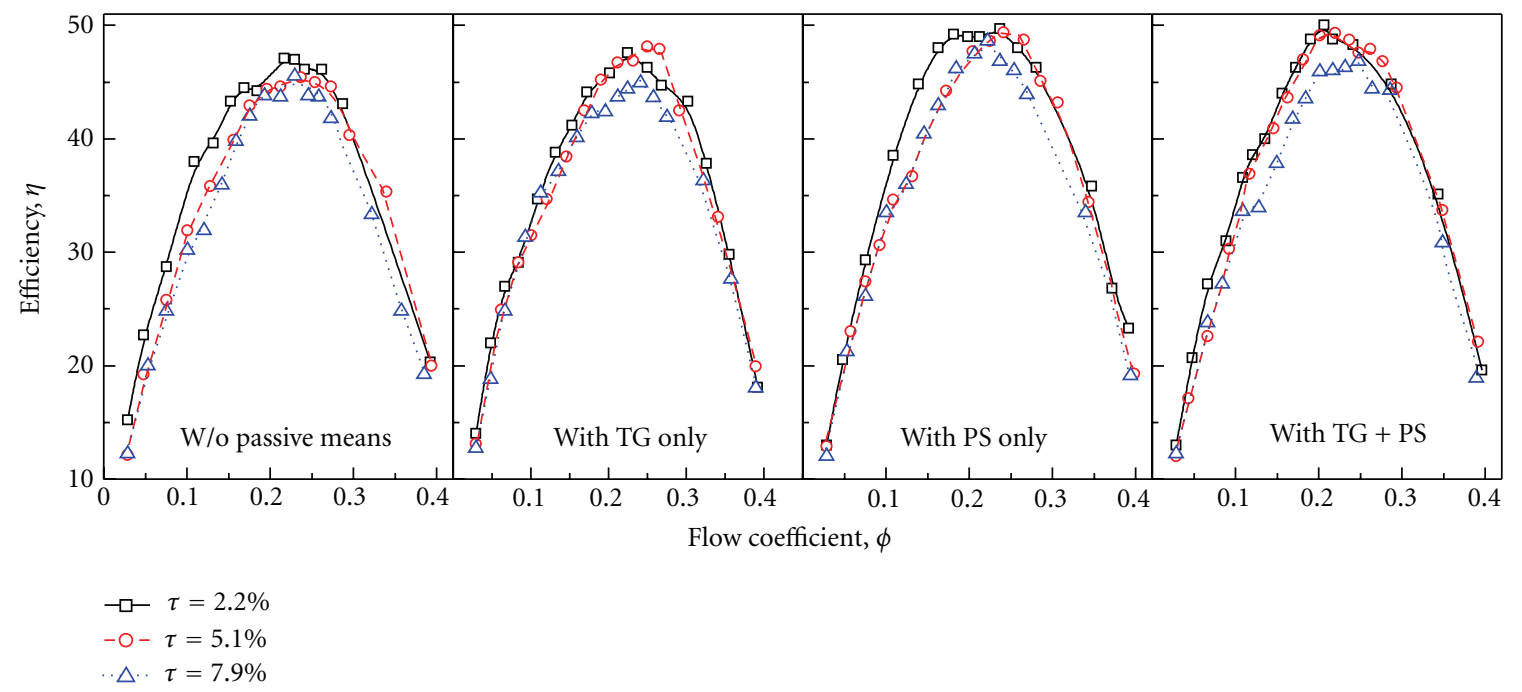

FIgURE 6: Performance characteristics of the centrifugal compressor ( $\eta$ versus $\phi)$ : effect of tip clearance.

at nearly the same flow coefficient for the three clearances tested. However, for configuration with PS, this benefit is not much pronounced. Thus, it can be concluded that TG has a beneficial effect of increased operating range, at lower value of tested clearance, although there is nominal change in $\psi$ and $\eta$. The trends of $\eta$ versus $\phi$ curves (Figure 6) are similar to those of $\psi$ versus $\phi$ curves. Efficiency decreases with increase in tip clearance. The decrease in efficiency is as much as $5 \%$ for basic configuration, whereas it is smaller for other configurations with passive means.

The effect of tip clearance on the most important performance parameters is presented in Table 4 and Figure 7. From the figure, it is evident that both PS and TG + PS configurations give higher energy coefficient compared to basic and TG configurations. Although TG configuration gives nearly the same value of energy coefficient (except at $\tau=7.9 \%)$ compared to the basic configuration, sensitivity of energy coefficient with tip clearance is reduced from $\tau=$ $5.1 \%$ onwards. Similar observation is made for TG + PS configuration compared with PS configuration. The value of $\phi$ at maximum efficiency remains nearly constant with tip clearance. However, the value of $\phi$ at maximum energy coefficient deceases with tip clearance. The value of $\phi$ at maximum energy coefficient is maximum for basic configuration followed by TG + PS, TG, and PS configurations.

The efficiency at the maximum value of $\psi$ is the lowest for basic configuration followed by TG, TG + PS, and PS configurations. However, the maximum efficiency is the highest for basic configuration followed by TG + PS, PS, and TG configurations. 


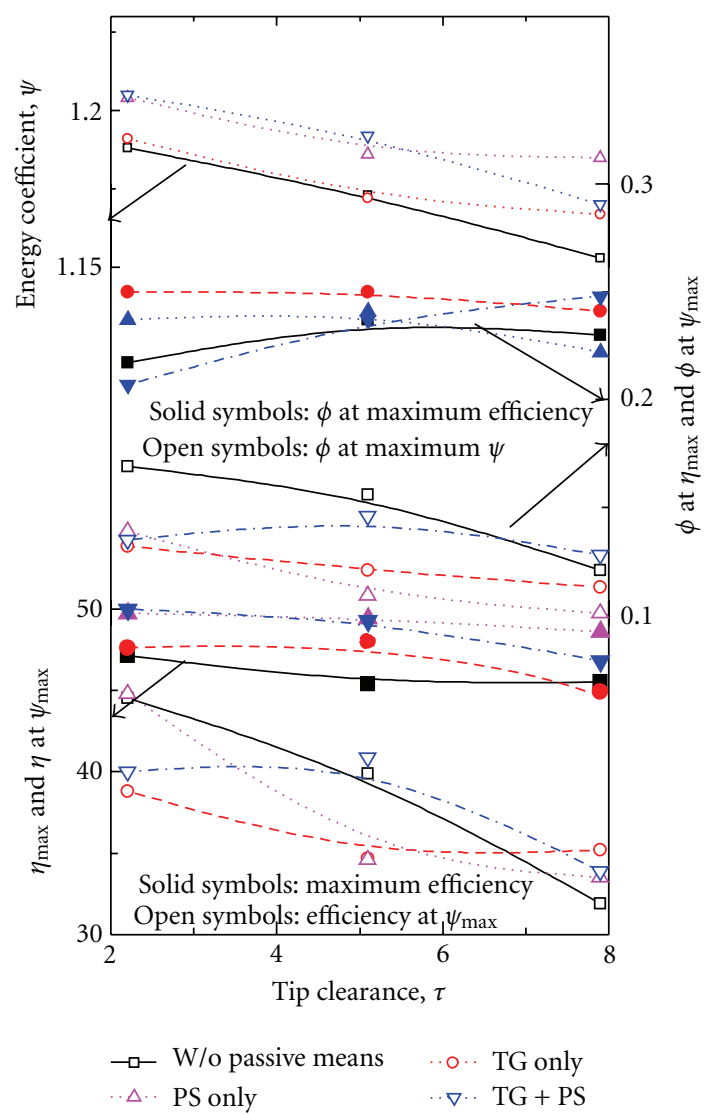

FIgURE 7: Effect of tip clearance on performance.

TABLE 4: Effect of tip clearance on $\psi_{\max }$ and $\eta_{\max }$.

\begin{tabular}{|c|c|c|c|c|c|c|}
\hline Details of configuration & $\tau(\%)$ & $\psi_{\max }$ & $\phi$ at $\psi_{\max }$ & $\eta$ at $\psi_{\max }$ & $\eta_{\max }$ & $\phi$ at $\eta_{\max }$ \\
\hline \multirow{3}{*}{ Without passive means } & 2.2 & 1.188 & 0.169 & 44.5 & 47.1 & 0.217 \\
\hline & 5.1 & 1.173 & 0.156 & 39.9 & 45.4 & 0.237 \\
\hline & 7.9 & 1.153 & 0.121 & 31.9 & 45.5 & 0.230 \\
\hline \multirow{3}{*}{ TG only } & 2.2 & 1.191 & 0.132 & 38.8 & 47.6 & 0.250 \\
\hline & 5.1 & 1.172 & 0.121 & 34.7 & 48.0 & 0.250 \\
\hline & 7.9 & 1.167 & 0.113 & 35.2 & 44.9 & 0.241 \\
\hline \multirow{3}{*}{ PS only } & 2.2 & 1.204 & 0.139 & 44.8 & 49.7 & 0.237 \\
\hline & 5.1 & 1.186 & 0.109 & 36.6 & 49.4 & 0.241 \\
\hline & 7.9 & 1.185 & 0.101 & 33.5 & 48.6 & 0.222 \\
\hline \multirow{3}{*}{$\mathrm{TG}+\mathrm{PS}$} & 2.2 & 1.205 & 0.135 & 40.0 & 50.0 & 0.207 \\
\hline & 5.1 & 1.192 & 0.146 & 40.9 & 49.3 & 0.237 \\
\hline & 7.9 & 1.170 & 0.128 & 33.9 & 46.8 & 0.248 \\
\hline
\end{tabular}

\section{Conclusions}

The following major conclusions are drawn from the present investigation.

(1) Configurations with partial shroud (PS) show higher energy coefficient and efficiency compared to other configurations. Partial shrouds have beneficial effects on increasing energy coefficient and efficiency of compressor.
(2) Other configurations, namely, TG and TG + PS, also have beneficial effects on the performance of the compressor. However, configurations TG*, TG + $\mathrm{TG}^{* *}$, and $\mathrm{TG}^{* * *}$ have detrimental effects on the performance of the compressor.

(3) Configuration 12 (basic configuration at $\tau=7.9 \%$ ) gives poor performance, that is, reduced operating range, reduced energy coefficient and efficiency over the entire operating range. 
(4) Turbulence generator (TG) has nominal effects on the energy coefficient and efficiency of the compressor. However, the operating range of the compressor is substantially increased.

(5) The sensitivity of energy coefficient from $\tau=5.1 \%$ onwards is reduced for TG configurations.

\section{Nomenclature}

$b: \quad$ Distance between the shroud and hub at the rotor exit $(\mathrm{m})$

$C_{d}$ : $\quad$ Velocity in delivery duct $(\mathrm{m} / \mathrm{s})$

$C_{s}: \quad$ Velocity in suction duct $(\mathrm{m} / \mathrm{s})$

$d: \quad$ Rotor diameter $(\mathrm{m})$

$N$ : $\quad$ Rotational speed of rotor $(\mathrm{rpm})$

$N_{c}$ : Coupling power (Watt)

$N_{\text {sh }}: \quad$ Shape number $=N \sqrt{ } V / W^{3 / 4}$

$P_{d}: \quad$ Delivery pressure $(\mathrm{Pa})$

$P_{s}$ : $\quad$ Suction pressure $(\mathrm{Pa})$

TG: Turbulence generator placed on the casing at $15 \mathrm{~mm}$ upstream the inducer leading edge

$\mathrm{TG}^{*}$ : Turbulence generator placed on the casing at $30 \mathrm{~mm}$ upstream the inducer leading edge

$\mathrm{TG}^{* *}$ : Turbulence generator placed on the hub at $30 \mathrm{~mm}$ upstream of the inducer leading edge

$\mathrm{TG}^{* * *}$ : Turbulence generator placed on the casing at $400 \mathrm{~mm}$ diameter

$t: \quad$ Rotor blade clearance $(\mathrm{m})$

$U: \quad$ Rotor tip speed $=(\pi d n / 60)(\mathrm{m} / \mathrm{s})$

$V: \quad$ Volume flow rate $\left(\mathrm{m}^{3} / \mathrm{s}\right)$

$W: \quad$ Specific work $\left(\mathrm{m}^{2} / \mathrm{s}^{2}\right)$

$\phi: \quad$ Flow coefficient (defined in the text)

$\gamma: \quad$ Power coefficient (defined in the text)

$\eta: \quad$ Efficiency (defined in the text)

$\psi: \quad$ Energy coefficient (defined in the text)

$\rho: \quad$ Density of air $\left(\mathrm{kg} / \mathrm{m}^{3}\right)$

$\tau$ : $\quad$ Tip clearance as a percentage of rotor blade height at exit $=\left(t / b_{2}\right) \times 100$.
[3] Y. Senoo, "Mechanics on the tip clearance loss of impeller blades," Journal of Turbomachinery, vol. 113, pp. 581-597, 1991.

[4] M. Ishida, H. Ueki, and Y. Senoo, "Effect of blade tip configuration on tip clearance loss of a centrifugal blower," Journal of Turbomachinery, vol. 112, no. 1, pp. 14-18, 1990.

[5] J. Tang, T. Turunen-Saaresti, and J. Larjola, "Use of partially shrouded impeller in a small centrifugal compressor," Journal of Thermal Science, vol. 17, no. 1, pp. 21-27, 2008.

[6] A. Akturk and C. Camci, "Axial flow fan tip leakage flow control using tip platform extensions," Journal of Fluids Engineering, vol. 132, no. 5, Article ID 051109, 10 pages, 2010.

[7] A. Akturk and C. Camci, "Tip clearance investigation of a ducted fan used in VTOL UAVs, part 1: baseline experiments and computational validation," in Proceedings of the ASME Turbo Expo 2011, 2011, Paper no. GT2011-46356.

[8] A. Akturk and C. Camci, "Tip clearance investigation of a ducted fan used in VTOL UAVs, part 2: novel treatments via computational design and their experimental validation," in Proceedings of the ASME Turbo Expo 2011, 2011, Paper no. GT2011-46356.

[9] F. Kameier and W. Neise, "Experimental study of tip clearance losses and noise in axial turbomachines and their reduction," Journal of Turbomachinery, vol. 119, no. 3, pp. 460-471, 1997.

[10] N. Sitaram and R. Thakar, "Performance improvement of a low aspect ratio axial flow compressor by means of turbulence generator," Journal of Aerospace Science and Technology, vol. 59, no. 1, pp. 21-32, 2007.

[11] N. Sitaram and B. Pandey, "Tip clearance effects on a centrifugal compressor," Journal of The Aeronautical Society of India, vol. 42, no. 4, pp. 309-315, 1990.

[12] L. F. Schumann, D. A. Clark, and J. R. Wood, "Effect of area ratio on the performance of a 5.5:1 pressure ratio centrifugal impeller," Journal of Turbomachinery, vol. 109, no. 1, pp. 1019, 1987.

\section{Subscript}

2: Tip.

\section{Acknowledgments}

The authors would like to thank the faculty, technical staff and administrative staff, of Thermal Turbomachines Laboratory for their help and encouragement during the course of the present investigation.

\section{References}

[1] R. C. Pampreen, "Small turbomachinery compressor and fan aerodynamics," Journal of Engineering for Power, vol. 105, no. 2, pp. 251-256, 1983.

[2] Y. Senoo and M. Ishida, "Deterioration of compressor performance due to tip clearance of centrifugal impellers," Journal of Turbomachinery, vol. 109, no. 1, pp. 55-61, 1987. 

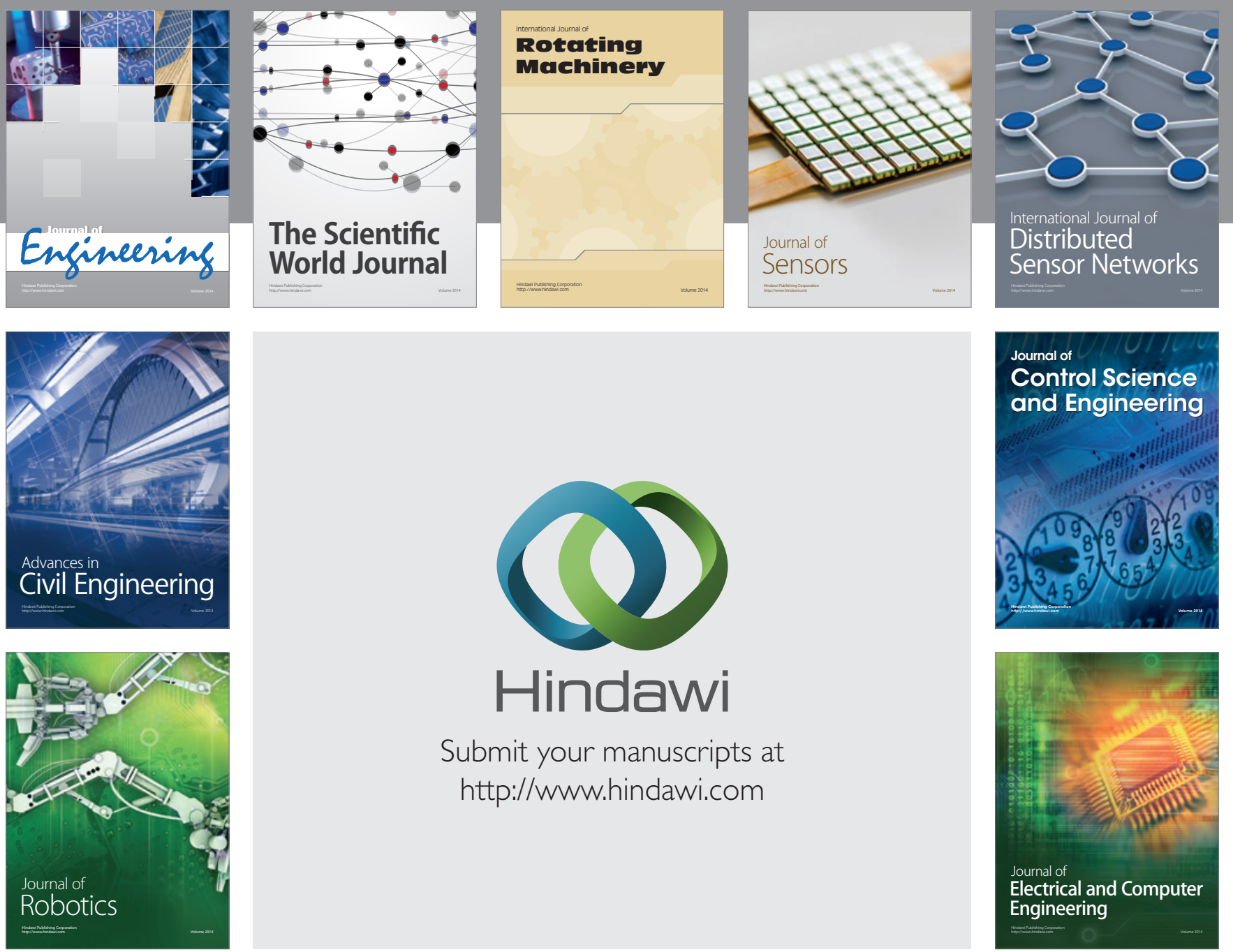

Submit your manuscripts at

http://www.hindawi.com
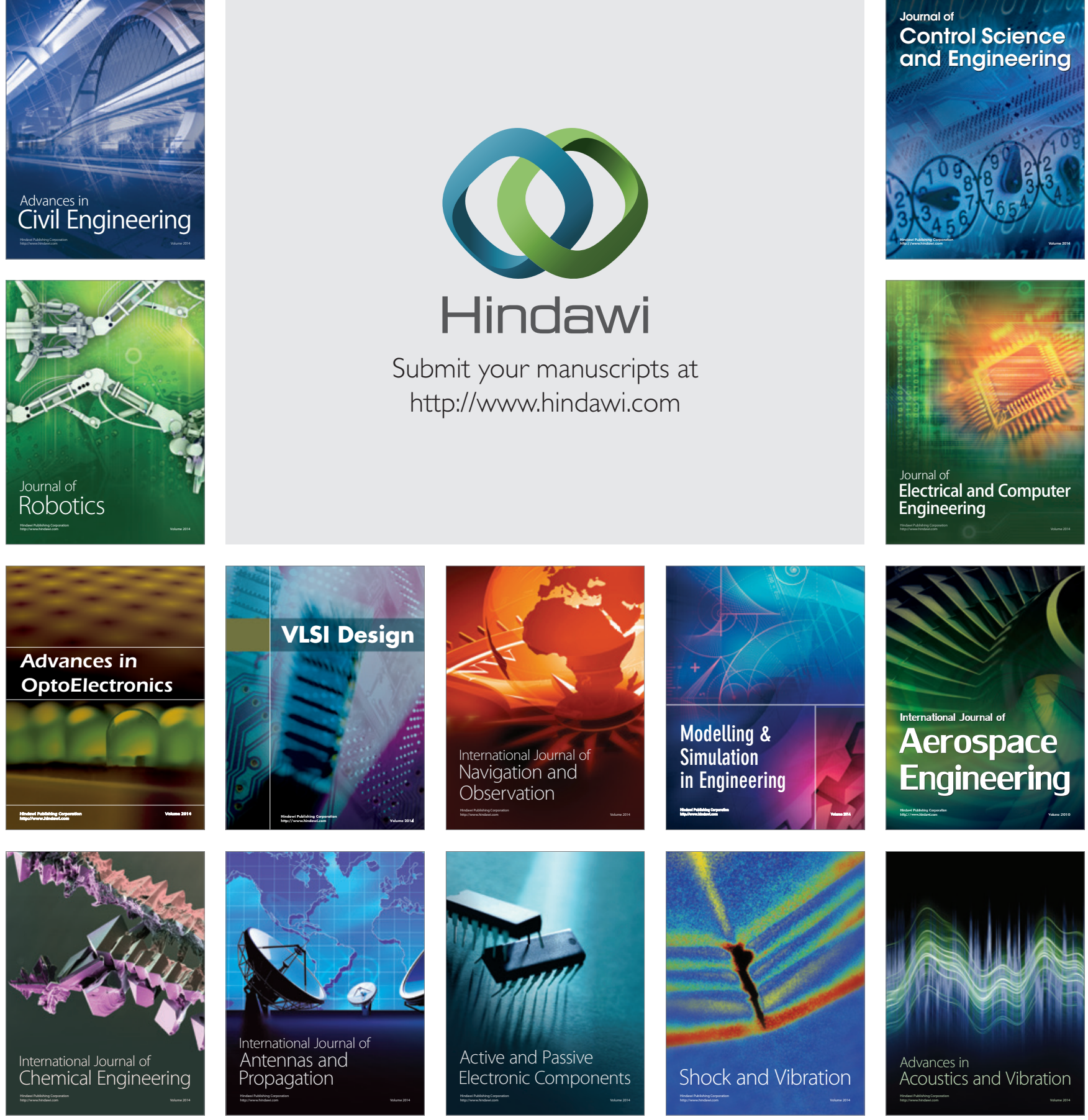